\title{
Böceklerde ebeveyn koruması
}

\author{
Rukiye TANYER $\dot{I}^{1}{ }^{* *}$, Ünal ZEYBEKOĞLU ${ }^{2}$ \\ ${ }^{1}$ Sinop Üniversitesi, Fen Edebiyat Fakültesi Biyoloji Bölümü, Sinop \\ ${ }^{2}$ Ondokuzmayls Üniversitesi, Fen Edebiyat Fakültesi Biyoloji Bölümü, Samsun \\ Gelis Tarihi (Recived Date): 26.05.2017 \\ Kabul Tarihi (Accepted Date): 26.09.2017
}

\section{Özet}

Ebeveyn koruması, doğacak veya yumurtadan çıkacak olan yavruların yaşam şansını artırmak için sergilenen sosyal bir davranıştır. Hayvan grupları arasında dikkat çekici bir çeşitlilik göstermektedir. Yavru bakımı konusunda, farklı hayvan taksonlarının izlediği çeşitli modeller bulunmaktadır. En temel haliyle bu modeller, ebeveynlerin birlikte bakımı üstlenmeleri veya ebeveynlerden sadece dişinin veya erkeğin bu davranışı göstermesi şeklindedir. Ebeveyn koruması, evrimsel biyoloji ve davranışsal ekolojinin de çeşitli sorularla ele aldığı önemli konulardan biridir. Özellikle memeliler ve kuşlarda daha yaygın olan bu davranış, hayvanlar aleminin en çeşitli grubu olan böceklerde de nadir de olsa görülmektedir. Böceklerde, yumurtaları ve yavruları koruma davranışı, çok yaygın olmasa da en az 13 takımda evrimleştiği düşünülmektedir Bu makalede, farklı böcek taksonlarında görülen ebeveyn koruması, daha önce yapılan çalışmalar çerçevesinde değerlendirilmiştir.

Anahtar Kelimeler: Ebeveyn koruması, maternal koruma ve böcekler.

\section{Parental care in insects}

\begin{abstract}
Paternal care is a social behavior that is displayed to increase survival of offspring nestling or hatching. It difers remarkably in animal taxa. There are various models of parental care that are followed by different taxa. At its most basic these models are, the way in which parents take care together or one of parents mother or father show this behaviour. Parental care's also one of the most important issues which is handled by evolutionary biology and behavioral ecology. This behavior is a common behavior especially among mammals and birds, but it is also rarely seen among insects which is the most varied group of the animalia. In insects, behavior to protect eggs and offspring is thought to have evolved in at least 13 orders although not very common. In this
\end{abstract}

\footnotetext{
"Rukiye TANYERİ, rtanyeri@ sinop.edu.tr, http://orcid.org/0000-0001-9994-8783

Ünal ZEYBEKOĞLU, unalz@omu.edu.tr, http://orcid.org/0000-0003-1646-5999
} 
article, care patterns observed in different insect taxa have been evaluated in the frame of previous studies.

Keywords: Paternal care, maternal care and insects

\section{Giriş}

Dünyaya farklı gelişim şekli ile gelen canlılar, başlangıçta kendilerini koruyamaz veya genel anlamiyla kendilerine bakamazlar. Ebeveynlerden birinin, bazen de her ikisinin birlikte ilgisine gereksinimleri vardır. Başlangıçta sergilenen davranışların tümü, yavru için ilgi isteme, ebeveyn için de ilgi gösterme, koruma, sorumluluk olarak tanımlanabilir. Bazı araştırıcılar bu duruma dikkat = attenti davranış, bazıları ana-baba $($ parental-ebeveyn $)=$ maternal davranış isimlerini kullanmaktadırlar [1] .

Omurgasızların büyük bölümünde ve diğer hayvan gruplarının bir kısmında, yumurta içindeki besin maddesi dışında ebeveynlerce sergilenen bir yavru bakımı yoktur. Bazı türlerde yumurtaları, yumurtadan çıkan ilk yavruları avcılardan, kurumaktan ve farklı bazı çevresel tehlikelerden korumayı amaçlayan davranışlar gözlenmektedir. Memeliler ve kuşlarda, gelişen embriyoyu bir plasenta ya da vitellüs aracılığıyla koruma, doğumdan ya da yumurtadan çıkışından sonra avcı ve parazitlerden koruma, sonrasında çeşitli besinleri sağlama davranışlarıyla sıklıkla karşılaşılmaktadır. Sürüngenler, kurbağalar, balıklar ile omurgasızlardan yumuşakçalar gibi çeşitli gruplarda ebeveyn bakımı daha az görülmektedir [2].

Yavru bakımı konusunda, farklı hayvan taksonlarının izlediği çeşitli modeller bulunmaktadır. En temel haliyle bu modeller, ebeveynlerin birlikte bakımı üstlenmeleri, ebeveynlerden sadece dişinin veya erkeğin bu davranışı göstermesi şeklindedir. Ancak dişilerin bu konuda daha fedakâr olduğu söylenebilir. Böceklerde yumurtaları ve yavruları koruma davranışı, çok yaygın olmasa da en az 13 takıma bağlı türlerde evrimleştiği düşünülmektedir [3]. En yaygın görülen bakım, yavruları avcılardan koruma veya yeni çıkan yavrulara besin temin edip sunma şeklindedir. Yavruların yaşama şansını artıran bu davranış şekilleri, neslin geleceğini teminat altına almanın en belirgin yollarından biridir. Böceklerde görülen yavru bakımı üç farklı şekilde olabilmektedir. Bunlardan ilki fiziksel koruma (yuva ya da galeri oluşturma), ikincisi bekçilik olarak adlandırılan davranışsal model ve üçüncüsü ise alarm, toplanma ve savunma feromonlarını üretmeyi kapsayan kimyasal korumadır. Böcekler, bu yöntemlerden birini ya da birkaç mekanizmayı birlikte kullanırlar. Örneğin, Anechura bipunctata (Fabricius, 1831) (Dermaptera: Forficulidae) her üç yöntemi de kullanarak yavru bakımını gerçekleştirir [4].

Burada, böceklerde dişi ebeveynlerin yumurtalarını oluşturması, bırakması ve sonrasında gelişen yavruların kendi besinlerini karşılayabilecek duruma gelene kadar geçen sürede ebeveyn korumasının çeşitleri bildirilmiştir. 


\section{Ebeveyn koruması ve çeşitleri}

Yavru bakımındaki çeşitliliği açıklamak için kullanılan terminoloji kafa karıştırıcı olabilmektedir. Bu nedenle ebeveyn davranışlarını kategorize etmekte fayda vardır. Bu kategoriler aşağıda başlıklar halinde sunulmuştur.

\subsection{Yumurta oluşturma}

Dişi tarafindan yumurta içine protein ve lipid depolamak ebeveyn bakımının temel şekillerinden biridir. Buna ilaveten çeşitli antibodiler, hormonlar ve antioksidantlar da depolayabilmektedirler. Bunun yanında, bazı böcekler yumurtalarını koruyucu yapılar ya da kimyasallarla kaplayabilirler. Örneğin, Cryptocephalus hypochaeridis (L., 1758) (Coleoptera: Chrysomelidae) dişileri, salg1 ve fekal materyal kombinasyonundan oluşturdukları koruyucu bir yapıyla yumurtalarını kaplamak için ciddi bir zaman ve enerji harcarlar [5].

\subsection{Yumurta burakılacak alanın seçimi}

Dişiler, yumurtalara koruma sağlayacakları ve yumurtadan çıkan yavrular için gerekli besin kaynaklarının bulunabileceği alanları yumurta bırakma yeri olarak seçerler. Dişiler, yumurtalarını ooteka denilen bir kese içinde veya ovipozitörü ile uygun olan bir yere yerleştirirler [6].

Yumurta bırakma alanını, predatörlerin ve parazitoitlerin yumurtaları bulma veya ulaşma riskini en aza çekecek şekilde belirlerler. Aynı zamanda yumurtadan çıkan yavru için en uygun mikroklimatik koşulların olmasına da özen gösterirler. Pek çok çalışma, yumurtlama alanının nesillerin yaşama şansını artıran önemli bir etken olduğunu göstermektedir. Örneğin Culiseta longiareolata (Macqurat, 1831) (Diptera: Culicidae) yumurtalarını larval predatörlerinin olduğu havuzlara bırakmaktan kaçınırlar [5].

\subsection{Yuva yapımı}

Yuva yapımı omurgalılarda olduğu gibi bazı omurgasızlarda da görülen bir bakım şeklidir. Özellikle gerçek sosyal böcekler olan termitler, karıncalar, yaban arıları ve arılarda görülen yaygın bir davranıştır [7]. Çeşitli yaban arılarının çamurla oluşturdukları yuvalar ilginç örneklerden biridir. Bunun yanısıra galeri ve tünel benzeri yapılar oluşturan türler de mevcuttur [5].

\subsection{Yumurta bekçiliği ve yavruları düşmanlardan koruma}

Böceklerde görülen en yaygın ebeveyn koruması yumurta bekçiliğidir [8]. Çevredeki mevcut tüm tehditlerden yumurtaları koruma davranışı Lepidoptera, Dermaptera, Coleoptera ve Hemiptera takımlarının bazı türlerini de içeren farklı böcek gruplarında görülmektedir. Böcekler içerisinde ebeveyn bakımının en yaygın olduğu grup olan Hemiptera takımında dişilerin kitle halinde bıraktıkları yumurtalarının üzerinde bulunması tipik bir davranış olarak bilinmektedir. Elasmucha grisea (Linnaeus,1758) (Hemiptera: Acanthosomatidae) dişileri yumurtaların üzerine konuşlanırlar. Tectocoris diophthalmus (Thunberg, 1783) (Hemiptera:Scutelleridae) dişilerinde de aynı davranış görülmektedir [3].

Daha önce de bahsedildiği üzere, en yaygın ana-baba koruması, yavruları avcılardan korumaktır. Örneğin, Elasmucha cinsine ait türlerin dişileri yavrularının çok yakınında beklerler ve saldırı anında yavruların üzerine kapanıp kanatlarını çırparak avcıları uzaklaştırırlar. Bazı türlerde dişi ebeveyn tarafindan yapılan bu korumanın yavruların 
hayatta kalma başarısına etkisi ölçülmüştür. Örneğin Umbonia crassicornis (Amyot \& Serville, 1843) (Hemiptera: Membracidae) dişi ebeveynin yabani arı saldırılarına karşı yavrularını koruduğunda yavruların hayatta kalma oranı \% 94 iken, korumanın olmadığında bu oran \% 23' e düşmektedir.

U. crassicornis nimfleri dördüncü nimf dönemine dek kümeler halinde bulunurlar ve dişi ebeveynler predatör arılara karşı kanatlarını çırparak nimfleri korurlar [9]. Yine aynı türde, dişi ebeveynler farklı bir koruyucu davranış daha sergilerler. Olası tehditlerden yavrularını korumak için ince uzun pronotumları ile vızıltı benzeri ses çıkartırlar. Aynı zamanda nimfler de bir avcının varlığında senkronize titreşimler oluştururlar ve dişi ebeveynin tehlikenin olduğu noktaya gelmesini sağlarlar [10].

Yumurta korumasına ilginç bir örnek de Mimosestes amicus (Horn, 1873) (Coleoptera: Chrysomelidae) dişilerinin yumurtalarını, yumurta paraziti olan yabani arılardan korumak için sergilediği davranıştır. Dişiler parazitlerden ve kurumadan korumak için yumurtalarını üst üste gelecek şekilde yığar. Üstte kalan ve diğerlerine göre daha büyük olan yumurtalar alttakiler için kalkan görevi görür [11].

\subsection{Yumurtaların veya nimflerin ebeveynlerin sırtında taşınması}

Ebeveyn bakımında dikkat çeken çeşitlerden biri olan yumurtaların dişilerin ya da erkeklerin vücudu üzerinde taşınması Hemiptera takımının Belostomatidae ve Coreidae familyalarında görülmektedir. Dev su böceği Adebus herberti (Menke, 1960) (Hemiptera: Belostomatidae)'de erkek bireyler yumurtaları sırtlarında taşırlar. Bu şekilde, yumurtalarını avcılardan korur ve aynı zamanda gelişmeleri için gerekli mikrohabitatı da oluştururlar [12].

Hamam böceği, Thorax porcellana Saussure, 1862 (Dictyoptera: Blaberidae) 'da dişiler nimflerini sırtlarında taşırlar [10].

\subsection{Besin Temini}

Daha çok omurgalı gruplarında yaygın olsa da bazı böcekler de bu davranışı sergiler. Örneğin, leşle beslenen Nicrophorus vespilloides (Herbst, 1784) (Coleoptera: Silphidae) türünde dişi bireyler yavrularını ön sindirime uğrattıkları materyalle beslemektedirler. Yavruların beslenme açısından bağımsız oldukları süreçte ebeveyn bakımı çok yaygın değildir. Bu durum uzun ömürlü omurgalılarda görülebilse de, omurgasızlarda az da olsa bazı örneklere rastlanmaktadır. $N$. vespilloides larvaları 72 saatte besin alımı yönünden bağımsız olsalar da, ergin dişiler 48 saat daha yavrularıyla kalmaktadırlar [5]. Adomerus triguttulus (Motschulsky, 1886) (Hemiptera: Cydnidae) türünde dişi ebeveynler, hem nimfleri korur, hem de toprak altında oluşturdukları galerilerdeki nimflere besin taşırlar [13].

\subsection{Trofik yumurta oluşturma}

Crespi (1992) trofik yumurtaları, gelişmemiş yumurtalar ya da dişiler tarafından yavruları beslemek için üretilen yumurta benzeri yapılar olarak tanımlamaktadır [14]. Ergin olmayan bireylerin beslenmesi için kullanılan bu yapıların, pek çok farklı hayvan taksonu için de söz konusu olduğu bildirilmiştir. Böceklerde ise bu davranış şekli gerçek sosyal böceklerle ilişkilendirilmektedir. Arılar ve karıncalarda daha yaygın olduğu rapor edilmiştir $[15,16]$. Bu gruplar dışında Coleoptera, Neuroptera, Orthoptera, Hemiptera ve Psocoptera takımlarında da morfolojik olarak fertil yumurtalardan larva ve nimflerin beslenmesi için üretilen trofik yumurtaların olduğu bilinmektedir [17]. 
A. triguttulus ve Parastrachia japonensis (Scott, 1880) (Hemiptera: Parastrachiidae) ve Archipsocus gurneyi Mockford, 1953 (Psocoptera: Archipsocidae) türlerinde de bu davranış şekli bilinmektedir. Cylindrocaulus patalis (Lewis, 1883) (Coleoptera: Passalidae)'de diğer yumurtalardan farklı olarak daha açık renkte trofik yumurtalar oluştururlar ve üçüncü dönemdeki larvaları dişi bireyler bu yumurtalar ile besler [18]. Canthophorus niveimarginatus Scott, 1874 (Hemiptera: Cydnidae)'da aynı davranış görülmektedir. Dişi bireyler yuvadan uzaklaştığında oluşturulan trofik yumurtalar sayesinde nimfler besin ihtiyacını karşılamaktadır [19].

Yukarıda değinilen koruma çeşitleri bazı türlerde aynı anda da görülebilmektedir. Tingidae familyası için ilk olarak ebeveyn bakımı Walsh (1864) tarafından Gargaphia tiliae (Walsh, 1864) (Hemiptera: Tingidae) türünde bildirilmiştir [20]. Daha sonra Gargaphia cinsinin farklı türlerinde ve yine aynı familyanın Compseuta, Corythucha, Leptobyrsa cinslerine ait bazı türlerde bu ender davranış gözlemlenmiştir. Tüm bu türlerde koruma davranış1, yuva benzeri yapılara yumurtlama ve dişi ebeveyn tarafından kanat çırpılarak predatörlerin kovulması şeklindedir. Dişiler yavrularını dördüncü ya da beşinci nimf dönemine dek bu şekilde korumaktadırlar. Compseuta picta (Schouteden, 1923) (Hemiptera: Tingidae) nimflere bir avcı yaklaştığında kanat çırparak yavrularını korur. G. solani Heidemann, 1914 (Hemiptera: Tingidae) bireyleri ise hem yuva benzeri yapılar oluşturur hem de dişiler yumurtalarının bekçiliğini yapar [21, 22].

\subsection{Biparental bakım}

Yavru bakımını sadece erkek ya da dişi ebeveyn yapabildiği gibi her iki ebeveynin de (biparental) bakımda rol aldığı örnekler de mevcuttur. Her iki ebeveynin bakıma ve korumaya katıldığı model Dictyoptera, Coleoptera ve Hymenoptera takımlarında görülür. Bu takımlara ait türlerin bazıları toprak altına ya da ağaç oyuklarına yuva yaparlar ve ergin olmayan bireylere yuvada besin temin ederler.

Cryptocercidae (Dictyoptera) familyasına ait türler ağaçların çürüyen kısımlarında koloni oluşturarak yaşarlar. Erginleri yuvaları korur ve nimflerini bağırsak salgılarıyla besler. Tehlike anında her iki ebeveyn de savunmaya katılır. Cryptocercus kyebangensis Grandcolas, 2001'de nimflerin gelişimi, her iki ebeveynin bakımı üstlenmelerinden dolayı daha hızlı olmaktadır [23].

300000'den fazla türü barındıran ve en büyük böcek takımı olan Coleoptera takımında biparental bakımın görüldüğü en az beş familya mevcuttur. Bunlar, Scarabaeidae, Passalidae, Silphidae, Tenebrionidae ve Curculionidae'dir [24]. Scarabaeidae familyasında biparental bakım oldukça yaygındır. Yavrularını beslemek için hayvan dışkılarını yuvaya taşırlar. Güney Afrika'da dağılım gösteren Kheper nigoaeneu (Boheman, 1857) (Coleoptera: Scarabeidae)'da ekstrem bir bakım örneği görülür. Dişi ebeveyn, toprak altındaki yuvada yumurtadan erginin gelişmesine kadar ki sürede tek bir yavruyu kontrol altında tutar [25]. Silphidae familyasından Nicrophorus cinsine ait bazı türler yuvaya yavruları için leş taşırlar. Tenebrionidae familyasına ait tek bir tür Parastizopus armaticeps Peringuey bu davranışı gösterir. Ebeveynler, üreme zamanı kum zemine birlikte bir çukur kazarlar ve yumurtadan çıkan yavruların beslenmesi için çukurun içini taze bitki dalları ile doldururlar. Aynı zamanda erkekler yuva girişinin bekçiliğini de yapmaktadır [26]. Curculionidae familyasından Homoeometamelus cinsine ait türlerde benzer davranışlar bildirilmiştir. Bireyler, çiftleşme öncesi odacık oluştururlar ve her birine bir yumurta bırakırlar [27]. 


\section{Ebeveyn bakımının evrimsel biyolojideki önemi}

Ebeveyn koruması, evrimsel biyolojinin de önemli konularından biridir. Özellikle ebeveynlerden hangisinin yavrular için daha çok çaba sarf ettiği ve davranışın gelişimi üzerinde durulmaktadır. Yapılan çalışmalarda ebeveynlerden genellikle dişilerin daha fazla efor sarf ettiği bildirilmektedir. Queller (1997) bu durumu çoklu çiftleşme ve sperm rekabetinin erkeklerde babalık konusunda kararsızlığa neden olabileceğine bağlamaktadır [28, 29].

Subsosyal böcek taksonlarında, besin varlığı, rekabet ve doğal düşmanlar gibi çevresel faktörlerin oluşturduğu stres ebeveyn korumasının evriminde oldukça önemlidir. Böceklerde besin kaynağı, üreme modellerinin şekillenmesinde birincil seçilim baskısını oluşturur ve farklı gruplarda ebeveyn davranışlarının konvergent evrimine neden olmaktadır. Fitofag böceklerde ebeveyn bakımına neden olan en önemli etken diğer artropod düşmanlardır. Bu durum bitki dokularına yumurta bırakan predasyon ve parazitizm baskısına maruz kalan Hemiptera takımı türleri için de geçerlidir. Ebeveynler nesillerini korumak için etkileyici koruyucu davranışlar sergilemek zorundadır [13].

\section{Sonuç}

Ebeveyn koruması, ebeveynlerin gelecek nesilleri temin altına almak için sergilediği hayvan davranışlarından biridir. Ebeveynler yavrularının yaşam şansını artırmak için enerji ve zaman harcamaktadırlar. Farklı çevresel tehditlerden korumak için zaman zaman risk almaktadırlar. Bu yüzden ebeveyn koruması bazı kaynaklarda yatırım olarak ifade edilmektedir. Ebeveyn korumasının yararları ve ebeveynlerin gösterdiği çaba son yıllarda davranışsal ekolojinin önemli konularından biri haline gelmiştir. Özellikle kuş ve memeli gibi omurgalı hayvanlarda, bu davranışın yavrulara sağladığı avantajlar irdelenmiş, ebeveynlerin üreme davranışlarına ve üreme başarılarına nasıl bir etkisinin olduğu kapsamlı olarak çalışılmıştır. Omurgasız canlılarda yaygın olmasa da farklı grup ve taksonlarda görülmektedir. En az 13 farklı böcek takımında evrimleştiği bilinmektedir. Ancak, böceklerde bu davranış ile ilgili yapılan çalışmalar ise bazı türler ile sınırlı kalmıştır. Yapılan çalışmalarda özellikle larvaların yaşam şansını artırdığı görülmektedir. Dolayısıyla farklı böcek taksonlarında da görülebileceği düşünülmektedir. Böceklerde ebeveyn koruması ile ilgili çalışmalarda genellikle korumanın nasıl gerçekleştiğine odaklanılmıştır. $\mathrm{Bu}$ yüzden ebeveyn korumasının türlerin yaşam şansını ve türler arasındaki rekabeti nasıl etkilediğine dair ayrıntılı çalışmalara ihtiyaç duyulmaktadır.

\section{Kaynaklar}

[1] Öber A., Hayvan Davranışları (Temel Ögeler), 150, Nobel Yayın Dağıtım, Birinci bask1, (2007).

[2] Royle N.J, Smiseth P.T. ve Kölliker M., The Evolution of Parental Care, 376, Oxford University Press, (2012)

[3] Giffney, R.A. ve Kemp, Darrel J., Does It Pay to Care?: Exploring the Costs and Benefits of Parental Care in the Hibiscus Harlequin Bug Tectocoris diophthalmus (Heteroptera: Scutelleridae), Ethology, 120, 607-615, (2014). 
[4] Mas F., ve Kölliker M., Maternal care and offspring begging in social insects: chemical signalling, hormonal regulation and evolution, Animal Behaviour, 76, 1121-1131, (2008).

[5] Smiseth Per T., Kölliker M. ve Royle N. J., What is parental care? The Evolution of Parental Care, First Edition, Oxford University Press, 190-203, (2012).

[6] Gullan P.J. ve Cranstons P.S. (Çeviri Ed.:Prof. Dr. Ali Gök) Böcekler: Entomoljinin Ana Hatları, 580, Nobel Akademik Yayıncılık, (2012).

[7] Jones J.C. ve Oldroyd B.B., Nest Thermoregulation in Social Insects. Advances in Insect Physiology, 33, 153-191, DOI: 10.1016/S0065-2806(06)33003-2, (2006).

[8] Zink A.G., Quantifying the costs and benefits of parental care in female treehoppers, Behavioral Ecology, 14, 5, 687-693, (2003).

[9] Cocroft R.B., Antipredatör defense as a limited resource: unequal predaton risk in broods of an insect with maternal care, Behavioral Ecology, 13, 1, 125-133, (2002).

[10] Trumbo, Stephen T., The Evolution of Parental Care. First Edition. Oxford University Press, 2012. (Chapter (http://www.researcgate.net/publication/257644737) (04.01.2016).

[11] Deas J.B. ve Hunter M.S., Mothers modify eggs into shields to protect offspring from parazitism, Proceedings of the Royal Society B, 279, 847-853, (2012).

[12] Smith R.L., Male brooding behavior of the water bug Abedus herberti (Hemiptera: Belostomatidae), Annals of the Entomological Society of America, 69, 740-747, (1976).

[13] Nakahira T. ve Kudo S., Maternal Care in the Burrower Bug Adomerus triguttulus: Defensive Behavior, Journal Insect Behavior, 21, 306-316, (2008).

[14] Crespi, B.J., Cannibalism and trophic eggs in subsocial and eusocial insects. In: Cannibalism: ecology and evolution among diverse taxa. Edited by Elgar M.A. and Crespi B.J., Oxford University Press, Oxford. 176-213, (1992).

[15] Cassill D., Brood care strategies by newly mated monogyne Solenopsis invicta (Hymenoptera: Formicidae) queens during colony founding. Annals Entomology Society America, 95, 208-212, (2002).

[16] Koedam D., Velthausz P.H., Krift T. Van Der, Dohmen M.R ve Sommeijer M.J., Morphology of reproductive and trophic eggs and their controlled release by workers in Trigano (Tetragonisca) angustula Illiger (Apidae, Meliponinae) Physiological Entomology, 21, 289-296, (1996).

[17] Kudo Shiniichi, Nakahira T. ve Saito Y., Morphology of trophic eggs and ovarian dynamics in the subsocial bug Adomerus triguttulus (Heteroptera: Cydnidae), Canadian Journal of Zoology, 84, 723-728, (2006).

[18] Ento, K., Arya K., ve Kudo,S-I., Trophic egg provisioning in a passalid beetle (Coleoptera), European Journal of Entomology, 105, 99-104, (2008).

[19] Hironaka, M., Nomakuchi S., Iwakuma,S., ve Filippi L., Trophic egg production in a subsocialshield bug, Parastrachia japonensis Scott (Heteroptera:Parastrachiidae), and its functional value, Ethology, 111, 1089102, (2005).

[20] Weiss, H.B., Notes on Gargaphia tiliae Walsh, the linden lace-bug, Proceedings of Biological Society of Washington, 32, 165-168, (1919).

[21] Guidoti M., Tallamy D. W., Junior A. L. M., Maternal care in Gargaphia decoris (Heteroptera, Tingidae) with comments on this behavior within the genus and family, Revista Brasileira de Entomologia, 59, 2, 104-106, (2015). 
[22] Tallamy D.W. ve Iglay R.B., Maternal care in Compseuta picta an African Lace Bug (Heteroptera: Tingidae), Journal of Insect Behavior, 17, 2, 247-249, (2004).

[23] Park Y.C. ve Choe J.C., Effects of parental care on offsprinf growth in the Korean wood-feeding cockroach, Cryptocercus kyebangensis, Journal of Insect Physiology, 21, 71-77, (2003).

[24] Suzuki S., Biparental care in insects: Paternal care, life history, and the function of the nest. Journal of Insect Science: 13, Article No: 131, (2013).

[25] Edwards P.B. ve Aschenborn H.H., Maternal care of a single offspring in the dung beetle Kheper nigroaeneus: the consequences of extreme parental investment, Journal of Natural History, 23, 17-27 (1989).

[26] Rasa, O.A.E., Biparental investment and reproductive successin a subsocial desert beetle: the role of maternal effort, Behavioral. Ecology Sociobiology 43, 105-113, (1998).

[27] Jordal B.H., Sequeira A.S. ve Cognato A.I., The age and phylogeny of wood boring weevils and the origin of subsociality, Molecular Phylogenetics and Evolution, 59, 708-724, (2011).

[28] Queller, D.C. Why do females care more than males?, Proceedings of the Royal Society of London B: Biological Sciences, 264, 1555-1557, (1997).

[29] Manica, A. ve Johnstone, R.A., The evolution of paternal care with overlapping broods, American Naturalist, 164, 517-30, (2004). 